\title{
The Clinical Characteristics and Outcomes of COVID-19 Infections in Patients with Diabetes at a Tertiary Care Center in the UAE
}

\author{
Khadija Hafidh Saira Abbas Arhsee Khan Touseef Kazmi Zufana Nazir \\ Tahani Aldaham \\ Department of Medicine, Rashid Hospital, Dubai Health Authority, Dubai, UAE
}

\author{
Keywords \\ Diabetes mellitus · COVID-19 · Pneumonia • \\ Hyperglycemia · Pandemic
}

\begin{abstract}
Introduction: Uncontrolled glycemia is a well-recognized predictor of severity and deaths in previous respiratory viral outbreaks. We aimed to describe the characteristics and clinical course of patients with diabetes admitted with COVID-19 infection at a tertiary care center in the Emirate of Dubai, UAE, and assess the impact of hyperglycemia on the clinical outcomes. Methods: This study is a single-center, observational, retrospective chart review of 250 cases during the months of March to May 2020. Results: Among the 250 cases studied, 235 (94\%) were male. The mean age of the study group was $49.6 \pm 10.4$ years, with an age range of 2178 years. Diabetes was previously known in $166(66.4 \%)$ of the patients. The mortality $(p=0.03)$ and requirement for mechanical ventilation ( $p=0.02$ ) were higher for the cases with newly diagnosed diabetes when compared to those with pre-existing diabetes. Conclusion: Uncontrolled hyperglycemia adversely affects patients with COVID-19 infection. Newly diagnosed and previously undiagnosed hyperglycemia poses an added risk for complications. In the context of
\end{abstract}

karger@karger.com www.karger.com/dde

Karger $\stackrel{\text { ' }}{=}$

BOPEN ACCESS
(C) 2021 The Author(s)

Published by S. Karger AG, Base

This article is licensed under the Creative Commons AttributionNonCommercial-NoDerivatives 4.0 International License (CC BYNC-ND) (http://www.karger.com/Services/OpenAccessLicense) Usage and distribution for commercial purposes as well as any distribution of modified material requires written permission. the COVID-19 pandemic, optimizing glycemia in hospitalized patients is of paramount importance and screening to detect undiagnosed cases of diabetes may be particularly relevant.

(c) 2021 The Author(s)

Published by S. Karger AG, Basel

\section{Introduction and Objectives}

The emergence of the COVID-19 pandemic early this year brought about a seismic wave of infected cases globally, and our region was not spared. Recent publications from other regions highlighted diabetes as a significant risk factor for development of severe complications of COVID-19 infection [1-3]. The high transmission rate of SARS-CoV-2 together with a high prevalence of diabetes in our region is a cause for concern. Uncontrolled glycemia is a well-recognized predictor of severity and deaths in previous respiratory viral outbreaks, namely the 2009 pandemic influenza A (H1N1), SARS-CoV, and MERSCoV [4-6].

There are several factors linking diabetes with severity of infection. Hyperglycemia can induce, exacerbate, or prolong the acute inflammatory response [7]. It also causes an imbalance between coagulation and fibrinoly- 
sis, leading to increased levels of clotting factors and relative inhibition of the fibrinolytic system, promoting a pro-coagulant state [8]. In addition, it is thought that SARS-CoV-2 uses ACE2 as entry receptors, which are present on the islets of Langerhans. This can cause mild to fulminant damage to these cells, leading to clinical states varying from mild hyperglycemia to life-threatening diabetic ketoacidosis [9].

Limited data are available from the Middle East and Gulf region, where type 2 diabetes and prediabetes are highly prevalent [10]. The first case in the United Arab Emirates was reported on January 29, 2020 [11]. It was the first reported case in the Middle Eastern region. As of July 5, 2020, the total number of cases is 50,857 , with 321 deaths. 39,857 people have recovered [12]. We wished to explore the interplay of diabetes and COVID-19 based on our experience from one of the tertiary care centers in the UAE, which received a large volume of patients since the realization of the pandemic in February 2020.

\section{Patients and Methods}

\section{Design and Setting}

This is an observational retrospective study of adult patients with diabetes admitted with a laboratory-confirmed diagnosis of COVID-19 based on RT-PCR (real time polymerase chain reaction) assays from nasal or nasal and pharyngeal swabs, as per the WHO interim guidance. Data were retrieved from the patients' electronic health records.

\section{Study Population}

We included all adult patients admitted with a diagnosis of COVID-19 infection and hyperglycemia (known diabetes, prediabetes, and presence of hyperglycemia in the index admission) during the months of March to May 2020. We excluded all those with no history of diabetes (old and new). We also excluded people with diabetes if they have active malignancy (metastatic or nonmetastatic), on immunosuppressive medications; with advanced renal failure (on dialysis); with chronic lung disease (bronchiectasis and pulmonary fibrosis); or with liver cirrhosis.

\section{Assessment and Outcomes}

The primary objective of the study was to assess the impact of hyperglycemia on markers of disease severity and clinical outcomes. We also evaluated the length of hospital stay and outcomes (discharged or deceased). Baseline parameters were collected for all patients: age, gender, BMI, history of smoking, and presence of other comorbidities.

We examined the following laboratory markers of disease severity in our study: lymphocyte count, C-reactive protein, lactate dehydrogenase, D-dimer, and ferritin. These tests were ordered at the time of admission along with other investigations as part of the hospital's COVID-19 package.

COVID-19 and Diabetes: An Unpleasant Duo
Table 1. Characteristics of all the study subjects $(N=250)$

\begin{tabular}{|c|c|}
\hline \multicolumn{2}{|l|}{ Gender } \\
\hline Male & $235(94)$ \\
\hline Female & $15(6)$ \\
\hline \multicolumn{2}{|l|}{ Nationality } \\
\hline UAE national & $4(1.6)$ \\
\hline Expatriate & $246(98.4)$ \\
\hline \multicolumn{2}{|l|}{ Age } \\
\hline Mean age, years & $49.6 \pm 10.4$ \\
\hline $18-35$ years & $23(9.2)$ \\
\hline $36-50$ years & $103(41.2)$ \\
\hline$>50$ years & $124(49.6)$ \\
\hline Smokers & $14(5.6)$ \\
\hline Mean BMI & $28.2 \pm 5.1$ \\
\hline \multicolumn{2}{|l|}{ Comorbidities present prior to admission } \\
\hline Hypertension & $81(32)$ \\
\hline Ischemic heart disease & $23(9.2)$ \\
\hline \multicolumn{2}{|l|}{ Onset of symptoms } \\
\hline Duration in days & $5(3-7)$ \\
\hline \multicolumn{2}{|l|}{ Blood group } \\
\hline Group O & $77(30.8)$ \\
\hline Group A & $61(24.4)$ \\
\hline Group B & $62(24.8)$ \\
\hline Group $A B$ & $22(8.8)$ \\
\hline Mean $\mathrm{HbA1c}$ & $9(7-11)$ \\
\hline \multicolumn{2}{|l|}{ Severity of illness } \\
\hline Mild illness with no pneumonia & $48(19.2)$ \\
\hline Moderate illness with pneumonia & $123(49.2)$ \\
\hline Severe illness with severe pneumonia & $79(31.6)$ \\
\hline \multicolumn{2}{|l|}{ Oxygen therapy } \\
\hline Required & $55(22)$ \\
\hline Not required & $195(78)$ \\
\hline \multicolumn{2}{|l|}{ Outcome at completion of study } \\
\hline Discharged & $172(68.8)$ \\
\hline Transferred & $37(48.8)$ \\
\hline Inpatient & $16(6.4)$ \\
\hline Deceased & $24(9.6)$ \\
\hline
\end{tabular}

$N$ is the number of patients and the values in parentheses are percentages, and normal distribution is expressed as mean \pm standard deviation.

A chest radiograph (CXR), electrocardiogram, and blood grouping were also done for every patient on presentation as part of the hospital's policy for admissions. HbAlc was ordered for any patient who was known to have diabetes or had a random plasma glucose above $140 \mathrm{mg} / \mathrm{dL}$ on admission. Newly diagnosed diabetes was defined as $\mathrm{HbAlc}>6.5 \%$ with no previous history of the condition.

The severity of COVID-19 infection was defined on the basis of CXR findings. Mild infections were those who had symptoms and signs of URTI with normal CXR. Moderate infections had CXR findings but with less than $50 \%$ involvement of lung parenchyma, whereas severe cases had more than $50 \%$ involvement of lung parenchyma on CXR [13].

Dubai Diabetes Endocrinol J 2020;26:158-163 
Table 2. Subgroup analysis based on diabetes history

\begin{tabular}{|c|c|c|c|}
\hline & $\begin{array}{l}\text { Newly diagnosed } \\
(n=84)\end{array}$ & $\begin{array}{l}\text { Known diabetes } \\
(n=166)\end{array}$ & $p$ \\
\hline \multicolumn{4}{|l|}{ Severity of illness } \\
\hline Mild illness with no pneumonia & $10(11)$ & $38(22.9)$ & 0.053 \\
\hline Moderate illness with pneumonia & $41(48.8)$ & $82(49.4)$ & \\
\hline Severe illness with severe pneumonia & $33(39.3)$ & $46(27.7)$ & \\
\hline \multicolumn{4}{|l|}{ Mechanical ventilation } \\
\hline Required & $25(29.8)$ & $30(18.1)$ & 0.002 \\
\hline Not required & $59(70.2)$ & $136(89.9)$ & \\
\hline \multicolumn{4}{|l|}{ Outcome } \\
\hline Deceased & $14(16.7)$ & $11(6.6)$ & 0.002 \\
\hline
\end{tabular}

Patient population was subdivided into 2 categories based on their history of diabetes: newly diagnosed (diagnosis made during index admission) and previously known cases of diabetes. The groups were compared for differences in outcome.

\section{Statistical Analysis}

Quantitative variables were analyzed as median with interquartile range (IQR) for skewed data and as mean \pm SD for data with normal distribution. Qualitative variables were organized as a total number with percentages. Data entry and statistical analysis were done using SPSS v20.0 (IBM Corp., Armonk, NY, USA). The results were analyzed by using $\chi^{2}$ for qualitative variable, and MannWhitney and independent sample $T$ test for continuous data with skewed and normal distribution, respectively. Statistical significance was set at $p$ value $<0.05$.

\section{Results}

\section{Characteristics of Patients}

Among the 250 cases studied, 235 (94\%) were male. The mean age of the study group was $49.6 \pm 10.4$ years, with an age range of $21-78$ years. $166(66.4 \%)$ of the patients had pre-existing diabetes. Eighty-one (32\%) of the cases were hypertensive, and $23(9.2 \%)$ were known to have ischemic heart disease. The mean BMI for this cohort was $28.2 \pm 5.1 \mathrm{~kg} / \mathrm{m}^{2}$.

\section{General Findings}

Median duration of symptoms prior to presenting to the hospital was 5 days (IQR, 3-7 days). The patients were hospitalized with mild to moderate pneumonia in $49.2 \%$ of the study cohort, while $19.4 \%$ experienced mild COVID-19 illness without any features of pneumonia. $31.6 \%$ among the group presented with severe pneumonia.
Mode of oxygen delivery administered to the patients was by nasal cannula in $50 \%$ of the cases and $28 \%$ were managed on non-rebreather masks. Twenty-two percent of the patients required management with mechanical ventilation. At the time of study completion, $172(68.8 \%)$ had been discharged home, 16 (6.4\%) were still inpatient, and 37 (14.8\%) were transferred to other health care facilities. The median length of stay for the discharged patients was 19 days (14.5-28). Baseline characteristics of all study subjects are presented in Table 1.

\section{Interplay between Diabetes and COVID-19}

Laboratory parameters revealed median HbA1c: 9\% [IQR, 7-11\%], median C-reactive protein: 95 [IQR, 35159], lactate dehydrogenase: 338 [IQR, 249-452], ferritin: 885 [IQR, 458-1,494], and D-dimer: 0.88 ([IQR, 0.541.55], range 0.11-20), as summarized in Table 2. Largest proportion of patients belonged to blood group O (30.8\%) and blood group $\mathrm{AB}$ was the least common (8.8\%). There was a mortality rate of $10 \%(n=25)$ in the study group.

Newly diagnosed diabetes cases had higher requirements for mechanical ventilation $(p=0.002)$, and the mortality rate was noted to be higher $(p=0.002)$ in this group. This comparative subgroup analysis is represented in Figures 1-3.

\section{Discussion}

Our cohort of 250 cases is composed of predominantly male patients with an average age of 49 years. The relatively young age in comparison to what was reported in other countries is a reflection of the demographic popula- 


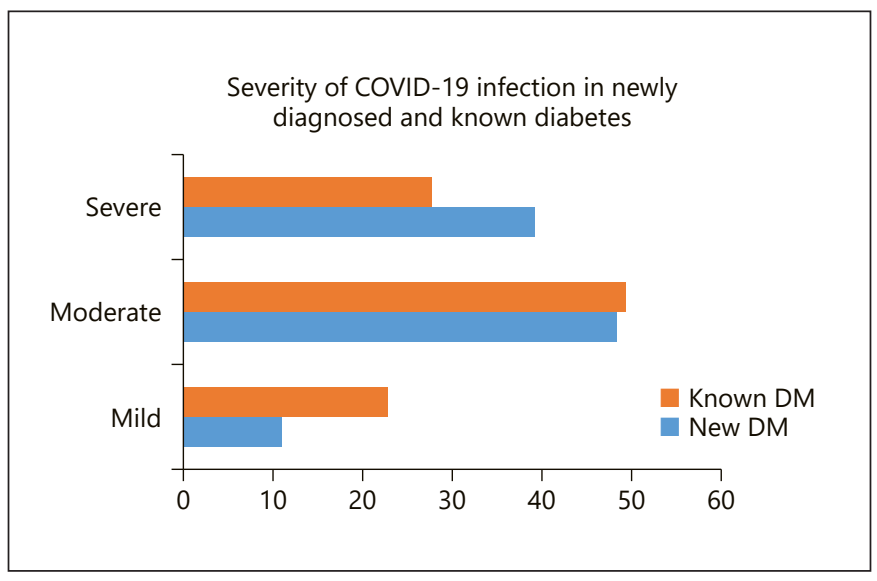

Fig. 1. Severity of COVID-19 infection.

tion dynamics of our region. The population is largely made up of migrant expatriates and so not surprisingly the patients are still in the working age group. A similar median age of 47 years was reported in Kuwait, also with a male preponderance.

Kuwait and the UAE have quite similar population demographics [14]. It is quite evident from the data to date that COVID-19 seems to have a predilection for the male gender. The cause for this gender disparity remains unclear.

There are other factors that may worsen the pre-existing hyperglycemic state in a patient with respiratory infection. This includes the use of steroid therapy, especially if prolonged, as well as the discontinuation of glucose sensitizers in patients with marked insulin resistance. On the other hand, the coexistence of diabetes with metabolic syndrome and obesity has detrimental effects on lung function, diminishing forced expiratory volume and forced vital capacity, thus impacting the recovery of damaged lung tissue from infections. Excessive ectopic fat deposition also predisposes to severe infection by potentiating the immune dysregulation that mediates the progression to critical illness and multi-organ failure [15].

The first dedicated study in hospitalized patients with diabetes and COVID-19 published in the journal Diabetologia in late May revealed troubling statistics. One in 10 people with diabetes in the study died of coronavirus within the first 7 days of being admitted. Furthermore, 1 in 5 people with diabetes were intubated and mechanically ventilated within the same length of time [16]. A comforting fact was that good glycemic control reduced both morbidity and mortality, as illus-

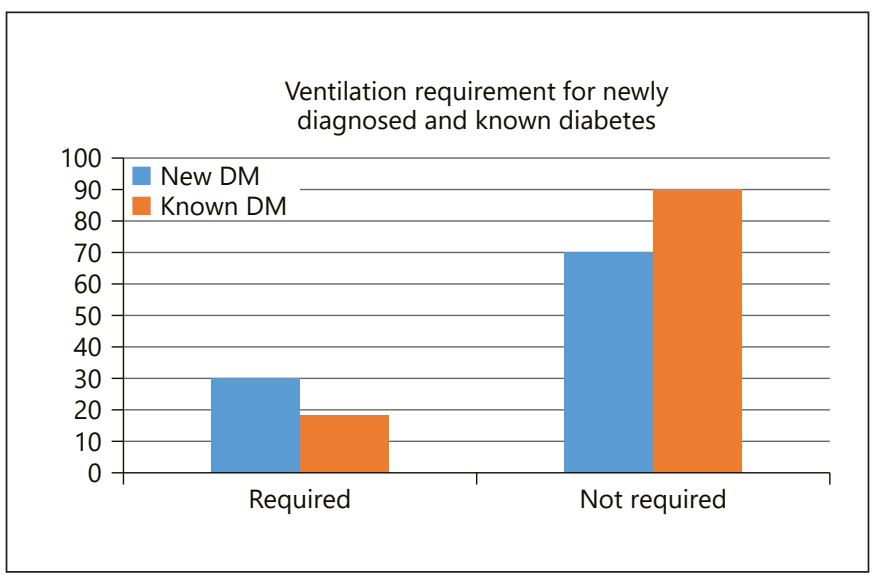

Fig. 2. Ventilation requirement.

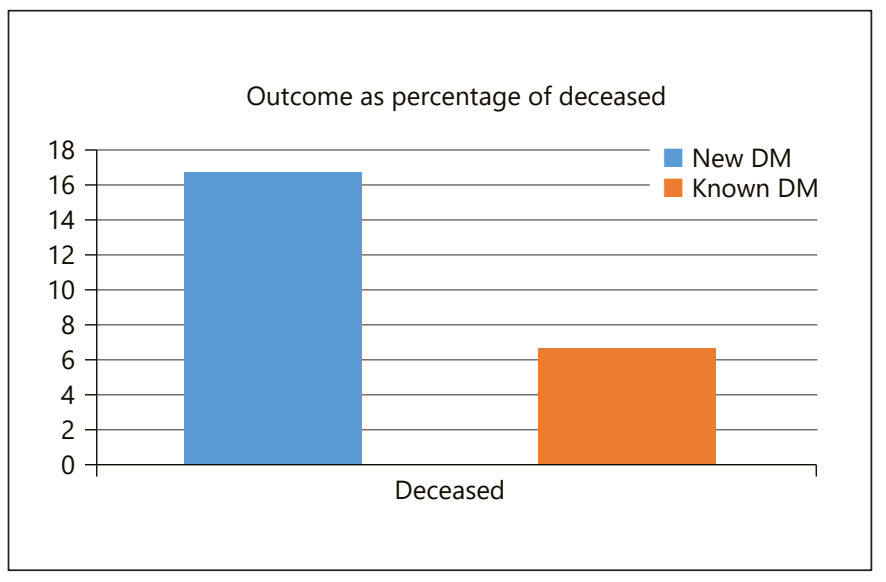

Fig. 3. Outcome of new versus known DM.

trated by Zhu et al. [17] in their cohort of 7,333 COVID-19 patients.

The large number of cases of COVID-19 with diabetes admitted to our center within 3 months reflects the high prevalence of diabetes in the Middle East as well as the fact that patients with diabetes who develop COVID-19 infection have a higher risk of being hospitalized. From our cohort of patients, approximately $66.4 \%$ were known to have diabetes, whereas the remaining $33.6 \%$ were diagnosed during admission. The fact that around one-third were unaware of underlying diabetes highlights the high number of patients in our region who remain undiagnosed [18]. It remains controversial whether their diabetes was specifically due to COVID-19-related injury of the pancreas or was discovered because of their infection [9]. We intend to follow this subset of patients closely to mon- 
itor their glycemic control and determine the outcome of their diabetes status. $80.8 \%$ of the hospitalized cohort had moderate-to-severe disease, whereas $19.4 \%$ of the patients had mild disease with no features of pneumonia. Mild cases (those not requiring oxygen) were transferred to makeshift isolation health care facilities in order to free hospital beds for the more severe cases. Twenty-two percent of the hospitalized patients required mechanical ventilation.

The most frequent blood type encountered in our cohort was blood group $\mathrm{O}$, though studies have reported a significantly lower risk of COVID-19 infection in patients with this blood group $[19,20]$. There are no definite associations between blood type and risk of complications from COVID-19 infection reported in the literature.

Clinical outcomes are dependent on many other factors including therapies received during hospitalization as well as associated comorbidities. We found that among our population of patients with diabetes, $32 \%$ had hypertension and 9.2\% had underlying ischemic heart disease, both of which are recognized as risk factors for poor outcomes in patients with COVID infection. Newly diagnosed cases had far worse outcomes compared to the patients with pre-existing diabetes in their requirement for mechanical ventilation and experienced a longer duration of stay at the hospital.

Mortality rate in our study was higher than the reported rate for the UAE due to the fact that our study analyzed only those with diabetes [21]. This was in concordance with a meta-analysis done by Kumar et al. [22], which analyzed 33 studies. The authors concluded an association of diabetes and mortality with an odds ratio $1.9(95 \%$ CI: 1.37-2.64). Mortality rate in our study was comparably higher and statistically significant $(p<0.05)$ in the newly diagnosed diabetic population, which is similar to the study performed by Li et al. [23].

Our study is limited in a number of ways; data were derived from a single center, and hence, it may not be representative of the UAE population in general. In addition, as the pandemic progressed and risk of our hospital facilities becoming overwhelmed became imminent the government took immediate measures to arrange for makeshift facilities, where a large number of mild cases were transferred. Furthermore, this was an observational study, where data were collected retrospectively. Patients received multiple anti-COVID treatments including corticosteroids during the course of their illness as per our national guidelines, which may have affected their clinical outcomes.

\section{Conclusion}

The present study emphasizes the intricate relationship between the COVID-19 and diabetes pandemics. This requires careful consideration by all health care systems. Particular attention is required in the populations with diabetes, which are already vulnerable to both acute and chronic complications. Newly diagnosed hyperglycemia poses an added higher risk of severe disease. Our study underscores the importance of optimizing glycemia in hospitalized patients and the value of public health screening to detect undiagnosed cases.

\section{Acknowledgements}

We wish to dedicate this work to all health-care providers at our hospital who worked diligently throughout the crisis.

\section{Statement of Ethics}

The study was conducted ethically in accordance with the World Medical Association Declaration of Helsinki. The study protocol was approved by DSREC (Dubai Scientific Research Ethics Committee), code number: DSREC-04/2020_17. All subjects gave their written informed consent.

\section{Conflict of Interest Statement}

The authors have no conflicts of interest to declare.

\section{Funding Sources}

No funding or sponsorship was received for this study.

\section{Author Contributions}

All named authors meet the International Committee of Medical Journal Editors (ICMJE) criteria for authorship for this article, take responsibility for the integrity of the work as a whole, and have given their approval for this version to be published. K.H. conceptualized the study design and protocol, supervised the data collection, and was involved in writing, review, and editing of the manuscript. S.A. was involved in the protocol review, data collection, writing and editing of the manuscript. A.K. designed the data collection tool and analyzed the data in its entirety. T.K. designed the data collection tool and contributed to the methodology of the study. Z.N. contributed to data collection and manuscript review. T.A. was involved with data collection and manuscript review.
Hafidh/Abbas/Khan/Kazmi/Nazir/ Aldaham 


\section{References}

1 Zhang Y, Cui Y, Shen M, Zhang J, Liu B, Dai $\mathrm{M}$, et al. Association of diabetes mellitus with disease severity and prognosis in COVID-19: a retrospective cohort study. Diabetes Res Clin Pract. 2020 May 22;165:108227.

2 Guo W, Li M, Dong Y, Zhou H, Zhang Z, Tian $\mathrm{C}$, et al. Diabetes is a risk factor for the progression and prognosis of COVID-19. Diabetes Metab Res Rev. 2020 Mar;31:e3319.

3 Mantovani A, Byrne CD, Zheng M, Targher G. Diabetes as a risk factor for greater COVID-19 severity and in-hospital death: a metaanalysis of observational studies. Nutr Metab Cardiovasc Dis. 2020 Jul 24;30(8):1236-48.

4 Schoen K, Horvat N, Guerreiro NFC, de Castro I, de Giassi KS. Spectrum of clinical and radiographic findings in patients with diagnosis of $\mathrm{H} 1 \mathrm{~N} 1$ and correlation with clinical severity. BMC Infect Dis. 2019 Nov 12;19(1): 964.

5 Yang JK, Feng Y, Yuan MY, Yuan SY, Fu HJ, $\mathrm{Wu}$ BY, et al. Plasma glucose levels and diabetes are independent predictors for mortality and morbidity in patients with SARS. Diabet Med. 2006 Jun;23(6):623-8.

6 Banik GR, Alqahtani AS, Booy R, Rashid H. Risk factors for severity and mortality in patients with MERS-CoV: analysis of publicly available data from Saudi Arabia. Virol Sin. 2016 Feb;31(1):81-4.

7 Moutschen MP, Scheen AJ, Lefebvre PJ. Impaired immune responses in diabetes mellitus: analysis of the factors and mechanisms involved. Relevance to the increased susceptibility of diabetic patients to specific infections. Diabete Metab. 1992 May-Jun;18(3): 187-201.
8 Schuetz P, Castro P, Shapiro NI. Diabetes and sepsis: preclinical findings and clinical relevance. Diabetes Care. 2011 Mar;34(3):771-8.

9 Yang JK, Lin SS, Ji XJ, Guo LM, Ji X, Ji X, et al. Binding of SARS coronavirus to its receptor damages islets and causes acute diabetes. Acta Diabetol. 2010 Sep;47(3):193-9.

10 Saeedi P, Petersohn I, Salpea P, Malanda B, Karuranga S, Unwin N, et al. Global and regional diabetes prevalence estimates for 2019 and projections for 2030 and 2045: results from the International Diabetes Federation Diabetes Atlas, 9th edition. Diabetes Res Clin Pract. 2019 Nov; 157:107843.

11 World Health Organization. United Arab Emirates: WHO coronavirus disease (COVID-19) dashboard. 2020.

12 UAE National Emergency Crises and Disasters Management Authority. UAE Coronavirus (COVID-19) updates. 2020.

13 Wong HYF, Lam HYS, Fong AH, Leung ST, Chin TW, Lo CSY, et al. Frequency and distribution of chest radiographic findings in COVID-19 positive patients. Radiology. 2020 Aug;296(2):E72-8.

14 Clinical characteristics of coronavirus disease 2019 (COVID-19) patients in Kuwait. 2020 Jul 5:196.

15 Sattar N, McInnes IB, McMurray JJV. Obesity a risk factor for severe COVID-19 infection: multiple potential mechanisms. Circulation. 2020 Jul 7;142(1):4-6.

16 Cariou B, Hadjadj S, Wargny M, Pichelin M, Al-Salameh A, Allix I, et al. Phenotypic characteristics and prognosis of inpatients with COVID-19 and diabetes: the CORONADO study. Diabetologia. 2020 Aug;63(8):150015.
17 Zhu L, She ZG, Cheng X, Qin JJ, Zhang XJ, Cai $\mathrm{J}$, et al. Association of blood glucose control and outcomes in patients with COVID-19 and pre-existing type 2 diabetes. Cell Metab. 2020 Jun 2;31(6):1068-e3.

18 Hamoudi R, Saheb Sharif-Askari N, Saheb Sharif-Askari F, Abusnana S, Aljaibeji H, Taneera J, et al. Prediabetes and diabetes prevalence and risk factors comparison between ethnic groups in the United Arab Emirates. Sci Rep. 2019 Nov 25;9(1):17437-7.

19 Ellinghaus D, Degenhardt F, Bujanda L, Buti M, Albillos A, Invernizzi P, et al. Genomewide Association Study of severe Covid-19 with respiratory failure. N Engl J Med. 2020 Oct 15; 383(16):1522-34

20 Li J, Wang X, Chen J, Cai Y, Deng A, Yang M. Association between $\mathrm{ABO}$ blood groups and risk of SARS $₫ \mathrm{CoV} \bowtie 2$ pneumonia. Br J Haematol. 2020 Jul;190(1):24-7.

21 Noor AU, Maqbool F, Bhatti ZA, Khan AU. Epidemiology of CoViD-19 Pandemic: recovery and mortality ratio around the globe. Pak J Med Sci. 2020 May;36(COVID19-S4):S7984.

22 Kumar A, Arora A, Sharma P, Anikhindi SA, Bansal N, Singla V, et al. Is diabetes mellitus associated with mortality and severity of COVID-19? A meta-analysis. Diabetes Metab Syndr. 2020 Jul-Aug;14(4):535-45.

$23 \mathrm{Li} \mathrm{H}$, Tian S, Chen T, Cui Z, Shi N, Zhong X, et al. Newly diagnosed diabetes is associated with a higher risk of mortality than known diabetes in hospitalized patients with COVID-19. Diabetes Obes Metab. 2020 May 29. 